\title{
SISTEM PAKAR DIAGNOSA PENYAKIT KEPITING BAKAU MENGGUNAKAN METODE FORWARD CHAINING
}

\author{
Yuswandi ${ }^{1}$, Dwi Yuli Prasetyo ${ }^{2}$ \\ 1,2Program Studi Sistem Informasi, Fakultas Teknik dan Ilmu Komputer \\ Universitas Islam Indragiri (UNISI) \\ Jl. Provinsi No. 01, Tembilahan Hulu, Indragiri Hilir, Riau \\ yuswandie10@gmail.com, dwiyuliprasetyo@gmail.com,
}

\begin{abstract}
ABSTRAK
Sistem pakar merupakan cabang dari kecerdasan buatan dan juga merupakan bidang ilmu komputer yang muncul seiring perkembangan ilmu komputer saat ini. Sistem ini bekerja untuk mengadopsi pengentahuan manusia ke komputer yang menggabungkan dasar pengetahuan (knowledge base) dengan sistem inferensi untuk mengantikan fungsi seorang pakar dalam menyelesaikan suatu masalah.

Kepiting bakau (Scylla serrata) yang dikenal juga kepiting lumpur banyak juga dijumpai diperairan Indonesia, terutama perairan payau yang banyak ditumbuhi oleh tanaman bakau.Untuk itu perlu adanya usaha budidaya bagi jenis crustacea yang memiliki nilai ekonomis tinggi. Namun disisi lain kurangnya pengetahuan masyarakat dalam membudidayakan kepiting bakau dan bagaimana cara mengatasi penyakit pada kepiting bakau menjadi masalah yang sangat serius bagi pembudidaya dan penampung kepiting bakau.

Untuk mangatasi masalah tersebut, maka dirancang suatu sistem pakar diagnosa penyakit pada kepiting bakau dimana sistem ini dapat mendiagnosa penyakit kepiting dengan meniru cara kerja pakar atau ahli sehingga system pakar ini dapat memberikan solusi kepada masyaakat tentang penanganan penyakit kepiting bakau. Dengan mengaplikasi metode Forward Chaining dan berbasis Web.
\end{abstract}

Kata kunci : Sistem Pakar, Forward Chaining, Kepiting bakau

\section{PENDAHULUAN}

Sistem pakar merupakan salah satu bagian dari kecerdasan buatan yang akhir-akhir ini mengalami perkembangan yang sangat pesat. Sistem ini dirancang untuk menirukan keahlian seorang pakar dalam menjawab pertanyaan dan menyelesaikan suatu permasalahan baik di bidang kesehatan atau kedokteran, bisnis, ekonomi dan sebagainya. Sistem pakar merupakan program komputer yang mampu menyimpan pengetahuan dan kaidah seorang pakar yang khusus. Sistem pakar sangat membantu untuk pengambilan keputusan, dimana sistem pakar ini dapat mengumpulkan dan menyimpan pengetahuan dari seseorang atau beberapa orang pakar dalam suatu basis pengetahuan (knowledge base) dan menggunakan sistem penalaran yang menyerupai seorang pakar dalam memecahkan masalah. Jadi, sistem pakar ini dapat memecahkan suatu masalah tertentu karena sudah menyimpan pengetahuan secara keseluruhan (Naser dan Zaiter, 2008).

Sistem pakar adalah suatu bidang ilmu bagian dari kecerdasan buatan yang mengandung pengetahuan-pengetahuan dan pengalaman-pengalaman yang dimasukkan oleh satu atau banyak pakar kedalam sebuah mesin atau perangkat lunak sehingga mesin tersebut mampu menyelesaikan masalah-masalah yang membutuhkan kepakaran atau keahlian manusia. Sehingga dengan adanya sistem pakar dapat membantu masyarakat dalam mendapat informasi yang diinginkan, dalam penelitian ini informasi yang diinginkan tentang penyakit dalam khususnya penyebab penyakit kepiting bakau.

Kepiting bakau (Scylla serrata) yang dikenal juga kepiting lumpur banyak juga dijumpai diperairan Indonesia, terutama perairan payau yang banyak ditumbuhi oleh tanaman bakau. Jenis kepiting ini disenangi masyarakat mengingat rasanya yang lezat dengan kendungan nutrisi sejajar dengan crustacea lain seperti halnya udang, Oleh karena itu kepiting ini banyak diminati baik dipasaran dalam negeri maupun luar negeri. Berkembangnya pangsa kepiting bakau (Scylla serrata) baik di dalam maupun di luar negeri adalah suatu tantangan untuk meningkatkan produksi secara berkesinambungan. Dengan mengandalkan produksi semata dari alam/tangkapan, jelas tidak 
sepenuhnya dapat diharapkan kesinambungan produksinya. Untuk itu perlu adanya usaha budidaya bagi jenis crustacea yang memiliki nilai ekonomis tinggi.

Di sisi lain produksi kepiting selama ini secara keseluruhan masih mengandalkan dari penangkapan di alam, yang kesinambungan prodsuksinya tidak dapat dipertahankan. Oleh karena itu sudah saatnya dilakukan usaha yang lebih rasional yaitu melalui sistem budidayanya.

Untuk mendukung perkembangan kepiting bakau disesuaikan dengan perkermbangan teknologi dalam bidang komputer dan informatika, kerumitan dan kesulitan dapat ditanggulangi dengan menyediakan suatu perangkat lunak (sistem pakar). Sistem pakar (expert system) adalah sistem yang berusaha mengadopsi pengetahuan manusia ke komputer, agar komputer dapat menyelesaikan masalah seperti layaknya para pakar (expert). Sistem pakar yang baik dirancang agar dapat menyelesaikan suatu permasalahan tertentu dengan meniru kerja dari para pakar/ahli.

Dari permasalahan diatas maka dapat di bangun rekayasa perangkat lunak dengan metode forward chaining untuk mendiagnosa penyebab penyakit kepiting bakau dengan menggunakan aplikasi berbasis web dengan judul penelitian "Sistem Pakar Diagnosa Penyakit Kepiting Bakau Menggunakan Metode Forward Chaining ".

Diharapan sistem yang dibuat dapat memberikan informasi dan solusi yang tepat kepada masyarakat mengenai penyakit kepiting bakau berdasarkan masukan gejala-gejala serta solusi.

\section{TINJAUAN PUSTAKA}

Sistem merupakan kumpulan elemen yang saling berkaitan yang bertanggung jawab memproses masukan (input) sehingga menghasilkan keluaran (output) (Kusrini, 2007).

Sistem adalah kumpulan atau himpunan dari unsur atau variabel-variabel yang saling terkait, saling berinteraksi, dan saling tergantung satu sama lain untuk mencapai tujuan (Tohari, 2014).

Selain itu sistem juga dapat didefinisikan sebagai sekumpulan objek-objek yang saling berelasi dan berinteraksi serta hubungan antar objek bisa dilihat sebagai satu kesatuan yang dirancang untuk mencapai satu tujuan yang telah ditetapkan.

Suatu sistem adalah jaringan kerja dari prosedur-prosedur yang saling berhubungan, berkumpul bersama-sama untuk melakukan suatu kegiatan atau menyelesaikan suatu sasaran tertentu (Kristanto, 2008).

Prosedur adalah suatu urutan operasi tulis-menulis dan biasanya melibatkan beberapa orang di dalam satu atau lebih departemen yang diterapkan, untuk menjamin penanganan yang seragam dari transaksi-transaksi bisnis yang terjadi.

Sistem juga merupakan kumpulan elemen-elemen yang saling terkait dan bekerja sama untuk memproses masukan (input) yang ditujukan kepada sistem tersebut dan mengolah masukan tersebut sampai menghasilkan keluaran (ouput) yang diinginkan.

\subsection{Sistem Pakar}

Sistem pakar merupakan cabang dari Artificial Intelligence (AI) yang cukup tua karena sistem ini mulai dikembankan pada pertengahan 1960.Istilah sistem pakar berasal dari istilah knowledge-based expert system.Isteilah ini muncul karena untuk memecahkan masalah, sistem pakar menggunakan pengetahuan seorang pakar yang dimasukkan kedalam komputer.Seseorang yang bukan pakar menggunakan sistem pakar untuk meningkatkan kemampuan pemecahan masalah, sedangkan seorang pakar menggunakan sistem pakar untuk knowledge assistant.Berikut adalah beberapa pengertian sistem pakar (Sutojo, 2011).

Ada beberapa definisi tentang sistem pakar menurut ahli, antara lain (T.Sutojo dkk, 2011) : a. Turban (2001).

Sistem pakar adalah sebuah sistem yang menggunakan pengetahuan manusia di mana pengetahuan tersebut dimasukkan ke dalam sebuah komputer dan kemudian digunakan untuk menyelesaikan masalah-masalah yang biasanya membutuhkan kepakaran atau keahlian manusia.

b. Jackson (1999).

Sistem pakar adalah sebuah program komputer yang mempresentasikan dan mempertimbangkan dengan pengetahuan dari beberapa subjek spesial dengan sabuah pandangan untuk meyelesaikan masalah-masalah atau memberikan nasehat.

c. Luger dan Stubblefield (1993).

Sistem Pakar adalah program yang berbasis pengetahuan yang menyediakan solusi 'kualitas pakar' kepada masalah-masalah dalam bidang (domain) yang spesifik.

\subsection{Struktur Sistem Pakar}


Ada dua bagian penting dari sistem pakar, yaitu ligkungan pengembangan (development environment) dan lingkungan konsultasi (consultation environment).Lingkungan pengembangan digunakan oleh pembuat sistem pakar untuk membangun komponen-komponennya dan memperkenalkan pengetahuan ke dalam knowledge base (basis pengetahuan).Lingkungan konsultasi digunakan oleh pengguna untuk berkonsultasi sehingga pengguna mendapatkan pengetahuan dan nasihat dari sistem pakar layaknya berkonsultasi dengan seorang pakar.gambar 1.1 menunjukkan komponen-komponen yang penting dalam sebuah sistem pakar (Sutojo dkk, 2011).

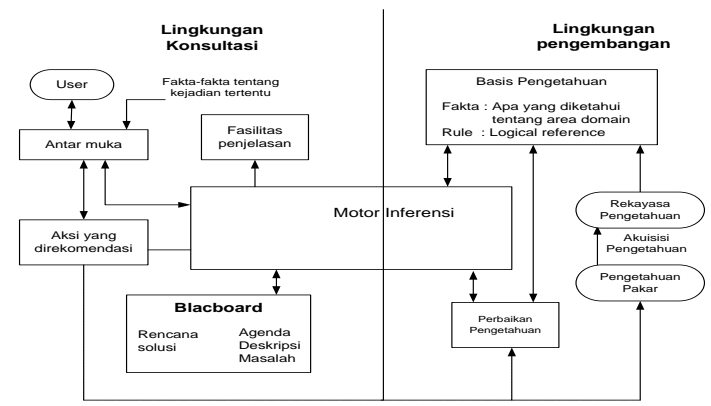

\section{METODE PENELITIAN}

Gambar 1 Struktur Sistem Pakar (Sumber: Sutojo dkk, 2011).

\subsection{Analisa Sistem}

Tahapan analisa sistem dilakukan setelah tahapan perencanaan sistem dan sebelum tahapan desain sistem. Tahapan analisa sistem merupakan tahapan yang kritis dan sangat penting karena kesalahan ditahap ini akan menyebabkan kesalahan ditahap selanjutnya.

\subsubsection{Analisa Kebutuhan Sistem}

Tahap analisis kebutuhan sistem adalah menjawab kebutuhan apa saja yang direkomendasikan untuk sistem baru yang akan diusulkan, yaitu menyangkut kebutuhan perangkat keras, perangkat lunak, informasi, dan kebutuhan pengguna atau user..

\subsubsection{Kebutuhan Perangkat Keras (Hardware)}

Perangkat Keras yang digunakan dalam perancangan ini adalah satu unit computer dengan spesifikasi minimum :

1. Processor Core (TM)2 Duo,

2. HDD Kapasitas 320 GB,

3. Memori Kapasitas 2 GB,

4. Monitor LED 15 Inc,

5. Keyboard dan Mouse.

6. Priinter Canon iP2770

\subsubsection{Kebutuhan Perangkat Lunak}

Dalam pembangunan sistem pakar untuk diagnose penyakit kepiting bakau ini menggunakan perangkat lunak dengan spesifikasi minimal sebagai berikut :

1. Windows 7.

2. XAMPP.

3. Macromedia Dreamwever CS.6

4. Mozilla Firefox / Google Chrome

5. Microsoft Office Word 2007

\subsubsection{Kebutuhan Penguna}

Brainware yaitu manusia sebagai pelaksana personal dari sistem pakar yang akan dirancang. Sistem pakar ini membutuhkan dua level brainware, diantaranya adalah :

1. Admin, yaitu yang mengendalikan aktifitas yang berhubungan dengan administrasi sistem. Admin mempunyai peranan yang sangat penting dan mempunyai hak akses untuk mengelola seluruh data yang ada, admin yang mengoperasikan sistem ini minimal bisa mengopersikan komputer dengan baik

2. Pengunjung (user), bertindak sebagai pengguna sistem pakar. Pengunjung mempunyai hak akses yang terbatas terhadap sistem.

\subsubsection{Analisis Akuisisi}


Tahap ini merupakan kegiatan pengumpulan pengetahuan dari sumber-sumber seperti pakar, buku, jurnal dan dari berbagai sumber. Pengetahuan yang dikumpulkan berkaitan dengan penelusuran macam-macam penyakit dalam dengan mengamati gejala-gejala yang timbul pada pasien.

Data-data dari berbagai sumber pengetahuan harus diolah sedemikian rupa sehingga menghasilkan solusi yang baik, terdapat beberapa jenis penyakit dalam diantaranya adalah sebagai berikut :

Tabel 1 Akuisisi Pengetahuan

\begin{tabular}{|c|c|c|}
\hline $\begin{array}{l}\mathbf{N} \\
\mathbf{0}\end{array}$ & Ciri-ciri & Penyakit \\
\hline 1 & $\begin{array}{l}\text {-Hidup dipernapasan/insang kepiting } \\
\text {-Berbentuk seperti teritip } \\
\text {-Hidup diperairan dangkal }\end{array}$ & $\begin{array}{l}\text { Octolasmis } \\
\text { mülleri }\end{array}$ \\
\hline 2 & $\begin{array}{l}\text {-Siklus hidup dimulai dari larva } \\
\text {-Hidup di dalam rongga tubuh Kepiting }\end{array}$ & $\begin{array}{l}\text { Loxothylacus } \\
\text { ihlei }\end{array}$ \\
\hline 3 & $\begin{array}{l}\text {-Ukuran panjang jantan } 5 \mathrm{~mm} \text { dan betina } 8 \\
\text { mm. } \\
\text {-menyerang insang dan karapas pada } \\
\text { kepiting }\end{array}$ & $\begin{array}{l}\text { Ascarophis } \\
\text { sp. }\end{array}$ \\
\hline 4 & $\begin{array}{l}\text {-Bentuk tubuh compressed } \\
\text {-bentuk mata sessile, } \\
\text {-memiliki } 7 \text { pasang kaki } \\
\text {-tidak memiliki karapaks, panjangnya 5-20 } \\
\text { mm } \\
\text {-berkembang biak dengan cara bertelur. }\end{array}$ & $\begin{array}{l}\text { Corophium } \\
\text { sp. }\end{array}$ \\
\hline 5 & $\begin{array}{l}\text {-bentuk tubuh lonjong } \\
\text {-menyerupai Cyclops } \\
\text {-berukuran } 1,5-2,0 \mathrm{~mm} \\
\text {-memiliki kaki renang } 4 \text { pasang } \\
\text { - Terdapat kaki berbentuk capit yang di } \\
\quad \text { gunakan untuk melekatkan diri pada } \\
\quad \text { insang } \\
\text {-Berkembang biak denngan cara bertelur }\end{array}$ & $\begin{array}{ll} & \text { Ergasilus } \\
\text { sp. } & \end{array}$ \\
\hline 6 & $\begin{array}{l}\text { - } \begin{array}{l}\text { bentuk tubuh seperti lonceng } \\
\text { berukuran 51,00 kuranng lebih 2,00 } \\
\text { um, } \\
\text { membentuk koloni tersusun pada } \\
\text { tangkai-tangkai yang bercabang dimana } \\
\text { satu tangkai terdapat satu indifidu dan } \\
\text { bersifat non-contractile } \\
\text { berkembang biak dengan pembelahan } \\
\text { diri. } \\
\text { Flagellanya ini terletak pada bagian } \\
\text { mulut. } \\
\text { Dengan organ sasaran insnag, badan, } \\
\text { ekor, kaki renang, kaki jalandan } \\
\text { karapaks. }\end{array} \\
\end{array}$ & Epistylis $s p$. \\
\hline
\end{tabular}




\begin{tabular}{|l|l|l|}
\hline 7 & - & Bentuk tubuh seperti hati berukuran 50- \\
& 70 um. & Chilodonella \\
& spp. \\
& berkembang dengan pembelahan & \\
& $\begin{array}{l}\text { Dengan organ sasaran insang, badan, } \\
\text { ekor, kaki renang, kaki jalan, dan } \\
\text { karapaks }\end{array}$ & \\
& & \\
\hline
\end{tabular}

\subsubsection{Pohon Keputusan}

Pohon keputusan merupakan grafik yang akan menjelaskan antar objek-objek yang akan dihubungkan dengan garis-garis berlabel ("ya" atau "tidak"), alasan digunakan pohon keputusan ini adalah karena lebih mudah dipahami. Berikut merupakan contoh pohon keputusan dengan kode penyakit pada kepiting bakau dapat dilihat pada gambar berikut :

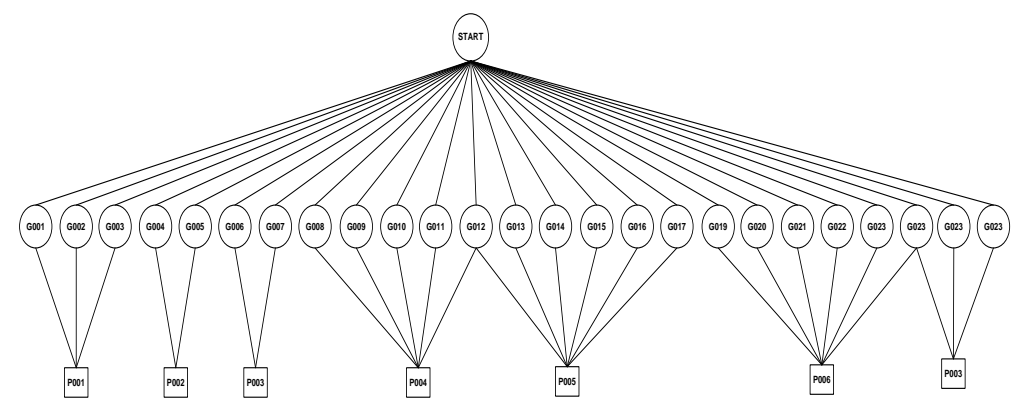

\subsubsection{Basis Pengetahuan}

Dalam pembuatan sistem pakar, fakta dan pengetahuan yang diperoleh diterjemahkan oleh pembuat sistem menjadi basis pengetahuan yang tersimpan dalam sistem pakar yang dibuat. Fakta tersebut di tampilkan dalam tabel keputusan, tabel penyakit, tabel gejala, dan tabel solusi.

Tabel 3.2 menunjukkan keputusan yang digunakan sebagai acuan dalam membuat pohon keputusan dan kaidah yang digunakan.

Tabel 2 Tabel Keputusan

\begin{tabular}{|c|l|l|l|l|l|l|l|}
\hline \multirow{2}{*}{$\begin{array}{c}\text { Kode } \\
\text { Ciri }\end{array}$} & \multicolumn{7}{|c|}{ Penyakit } \\
\hline & P001 & P002 & P003 & P004 & P005 & P006 & P007 \\
\hline CR001 & $\checkmark$ & & & & & & \\
\hline CR002 & $\checkmark$ & & & & & & \\
\hline CR003 & $\checkmark$ & & & & & & \\
\hline CR004 & & $\checkmark$ & & & & & \\
\hline CR005 & & $\checkmark$ & & & & & \\
\hline CR006 & & & $\checkmark$ & & & & \\
\hline CR007 & & & $\checkmark$ & & & & \\
\hline CR008 & & & & $\checkmark$ & & & \\
\hline CR009 & & & & $\checkmark$ & & & \\
\hline CR010 & & & & $\checkmark$ & & & \\
\hline CR011 & & & & $\checkmark$ & & & \\
\hline CR012 & & & & $\checkmark$ & & & \\
\hline CR013 & & & & & $\checkmark$ & & \\
\hline CR014 & & & & $\checkmark$ & & \\
\hline CR015 & & & & & $\checkmark$ & & \\
\hline CR016 & & & & & $\checkmark$ & & \\
\hline CR017 & & & & & $\checkmark$ & & \\
\hline CR018 & & & & & $\checkmark$ & & \\
\hline CR019 & & & & & & $\checkmark$ & \\
\hline CR020 & & & & & & $\checkmark$ & \\
\hline CR021 & & & & & & $\checkmark$ & \\
\hline CR022 & & & & & $\checkmark$ & \\
\hline CR023 & & & & & & $\checkmark$ & \\
\hline
\end{tabular}




\begin{tabular}{|l|l|l|l|l|l|l|l|}
\hline CR024 & & & & & & $\checkmark$ & \\
\hline CR025 & & & & & & & $\checkmark$ \\
\hline CR026 & & & & & & $\checkmark$ \\
\hline CR027 & & & & & & & $\checkmark$ \\
\hline
\end{tabular}

Pada tabel 3.2 diatas merupakan tabel keputusan yang berisikan keluhan pada buang air kecil dan jenis penyakit yang derita

Ket :

$\mathrm{P}=$ Penyakit

$\mathrm{K}=$ Keluhan sedangkan

*= Untuk menunjukkan penyakit sesuai dengan keluhannya.

Tabel 3 Data Penyakit

\begin{tabular}{|c|l|}
\hline $\begin{array}{c}\text { Kode } \\
\text { Penyakit }\end{array}$ & \multicolumn{1}{c|}{ Nama Penyakit } \\
\hline P001 & Octolasmis mülleri \\
\hline P002 & Loxothylacus ihlei \\
\hline P003 & Ascarophis $s p$. \\
\hline P004 & Corophium $s p$. \\
\hline P005 & Ergasilus $s p$. \\
\hline P006 & Epistylis $s p$. \\
\hline P007 & Chilodonella spp. \\
\hline
\end{tabular}

Pada tabel 3.3 adalah merupakan tabel data penyakit beserta kode penyakit seperti terlihat pada tabel diatas.

Tabel 4 Ciri Penyakit

\begin{tabular}{|c|l|}
\hline Kode Ciri & \multicolumn{1}{|c|}{ Ciri Penyakit } \\
\hline CR001 & Hidup dipernapasan/insang kepiting \\
\hline CR002 & Berbentuk seperti teritip \\
\hline CR003 & Hidup diperairan dangkal \\
\hline CR004 & Siklus hidup dimulai dari larva \\
\hline CR005 & Hidup di dalam rongga tubuh kepiting \\
\hline CR006 & Ukuran panjang jantan 5 mm dan betina 8 mm. \\
\hline CR007 & Menyerang insang dan karapas pada kepiting \\
\hline CR008 & Bentuk tubuh compressed \\
\hline CR009 & Bentuk mata sessile, \\
\hline CR010 & Memiliki 7 pasang kaki \\
\hline CR011 & Tidak memiliki karapaks, panjangnya 5-20 mm \\
\hline CR012 & Berkembang biak dengan cara bertelur. \\
\hline CR013 & Bentuk tubuh lonjong \\
\hline CR014 & Menyerupai Cyclops \\
\hline CR015 & Berukuran 1,5-2,0 mm \\
\hline CR016 & Memiliki kaki renang 4 pasang \\
\hline CR017 & $\begin{array}{l}\text { Terdapat kaki berbentuk capit yang di gunakan untuk } \\
\text { melekatkan diri pada insang }\end{array}$ \\
\hline CR018 & Berkembang biak denngan cara bertelur \\
\hline CR019 & Bentuk tubuh seperti lonceng \\
\hline CR020 & Berukuran 51, 00 kuranng lebih 2,00 um, \\
\hline CR021 & $\begin{array}{l}\text { Membentuk koloni tersusun pada tangkai-tangkai } \\
\text { yang bercabang dimana satu tangkai }\end{array}$ \\
\hline CR022 & Berkembang biak dengan pembelahan diri. \\
\hline &
\end{tabular}




\begin{tabular}{|l|l|}
\hline CR023 & Flagellanya ini terletak pada bagian mulut. \\
\hline CR024 & $\begin{array}{l}\text { Dengan organ sasaran insnag, badan, ekor, kaki } \\
\text { renang, kaki jalandan karapaks. }\end{array}$ \\
\hline CR025 & Bentuk tubuh seperti hati berukuran 50-70 um. \\
\hline CR026 & Berkembang dengan pembelahan \\
\hline CR027 & $\begin{array}{l}\text { Dengan organ sasaran insang, badan, ekor, kaki } \\
\text { renang, kaki jalan, dan karapaks }\end{array}$ \\
\hline
\end{tabular}

Tabel 3.5 Merupakan table pemberian solusi beserta kode solusi seperti terlihat pada tabel diatas. Solusi yang diberikan berdasarkan gejala dan jenis penyakit yang dialami oleh user.

\subsubsection{Pembuatan Rule}

Dalam perancangan menggunakan metode Forward Chaining ini, kaidah produksi dituliskan dalam bentuk pernyataan IF [premis] THEN [kesimpulan]. premis adalah gejala dan kesimpulan adalah jenis penyakit keluhan buang air kecil. Pada sistem pakar ini dalam satu kaidah dapat memiliki lebih dari satu gejala. Dan gejala-gejala tersebut dihubungkan dengan menggunakan logika and. Berikut pernyataannya :

Rule 1 : IF hidup di pernapasan atau insang kepiting

AND berbentuk Seperti Teritif

AND hidup di perairan dangkal

Then Octolasmis mülleri

Rule 2 : IF siklus hidup dimulai dari larva

AND hidup di dalam rongga tubuh kepiting

Then Loxothylacus ihlei

Rule 3 : IF ukuran panjang jantan $5 \mathrm{~mm}$ betina $8 \mathrm{~mm}$

AND menyerang insang dan karapas kepiting

THEN Ascarophis sp.

Rule 4 : IF bentuk tubuh compressed

AND urun bentuk mata sessile

AND memiliki 7 pasang kaki

AND tidak memiliki karapas panjang 5-20 mm

AND berkembang giak dengan cara bertelur

THEN Corophium sp.

Rule 5 : IF bentuk tubuh lonjong

AND menyerupai cyclop

AND berukuran 1,5-2 $\mathrm{mm}$

AND memiliki kaki renang 4 pasang

AND terdapat kaki berbentuk capit yang digunakan untuk melekatkan

diri pada inang

AND berkembang biak dengan cara bertelur

THEN Ergasilus sp.

Rule 6 : IF bentuk tubuh lonjong

AND berukuran 51 kurang lebih 2 um

AND membentuk koloni tersusun pada tangkai-tangkai yang bercabang.

AND berkembang biak dengan pembelahan diri

AND Flagellanya ini terletak pada bagian mulut.

AND degnan organ sasaran insang, badan, ekor, kaki renang, kaki jallan

dan karapaks

THEN Epistylis sp.

Rule 7 : IF bentuk tubuh seperti hati berukuran 50-70 um

AND berkembang biak dengan pembelahan

AND Dengan organ sasaran insang, badan, ekor, kaki renang, kaki

jalan, dan karapaks 
THEN Chilodonella spp.

\section{IMPLEMENTASI DAN PENGUJIAN SISTEM}

\subsection{Implementasi Sistem}

Aplikasi sistem pakar diagnosa penyakit kepiting bakau ini digunakan untuk dapat mendiagnosa penyakit pada kepiting bakau yang disebabkan oleh beberapa parasite ataupun jamur kepiting dengan menginputkan gejala-gejala yang ada pada kepiting. Berdasarkan basis pengetahuan sehingga penyakit dapat dideteksi.

Pada bagian admin pakar dimana semua kegiatan dalam sistem dapat dikontrol penuh dan dapat memanipulasi data serta dapat merubah yang mungkin di ubah serta penambahan inHalamanasi jenis-jenis penyakit. Admin dapat melakukan input data seperti data penyakit dan gejala yang dialami kepiting baka, solusi dan melihat laporan. Admin juga dapat melakukan pengeditan dan penghapusan data.

\subsubsection{Halaman Utama Aplikasi}

Halaman halaman utama merupakan Halaman yang pertama tampil ketika pengguna mengakses program. Adapun tampilannya dapat dilihat pada gambar berikut :

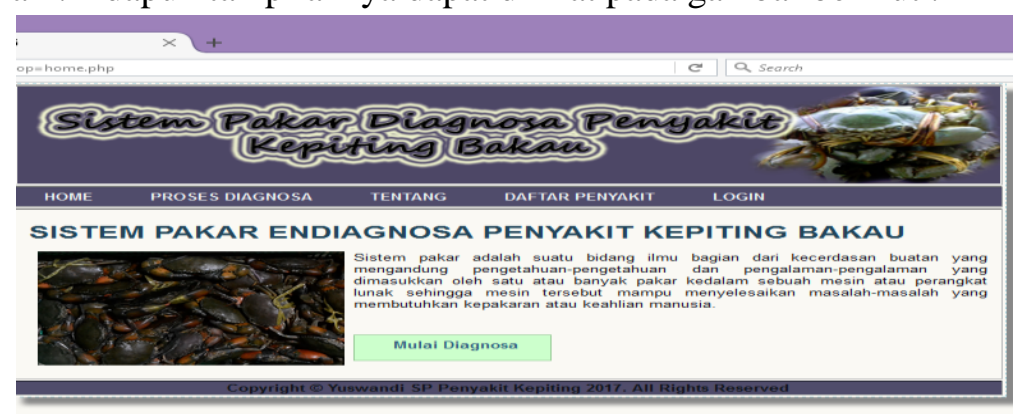

\subsubsection{Halaman Login Administrator}

Gambar 2 Halaman Utama Aplikasi

Halaman login administrator digunakan untuk melakukan login para administrator untuk masuk ke Halaman utama aplikasi. Tampilan Halaman login admin dapat dilihat pada gambar berikut :

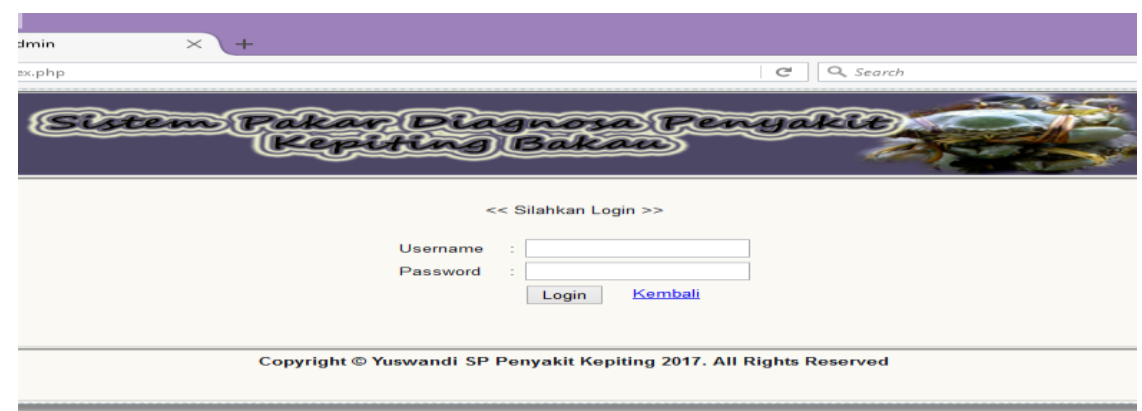

Gambar 3 Halaman Login Administrator

\subsubsection{Halaman Data Penyakit}

Halaman data penyakit digunakan untuk menginputkan data penyakit dan untuk menampilkan penyakit. Tampilannya seperti pada gambar berikut : 


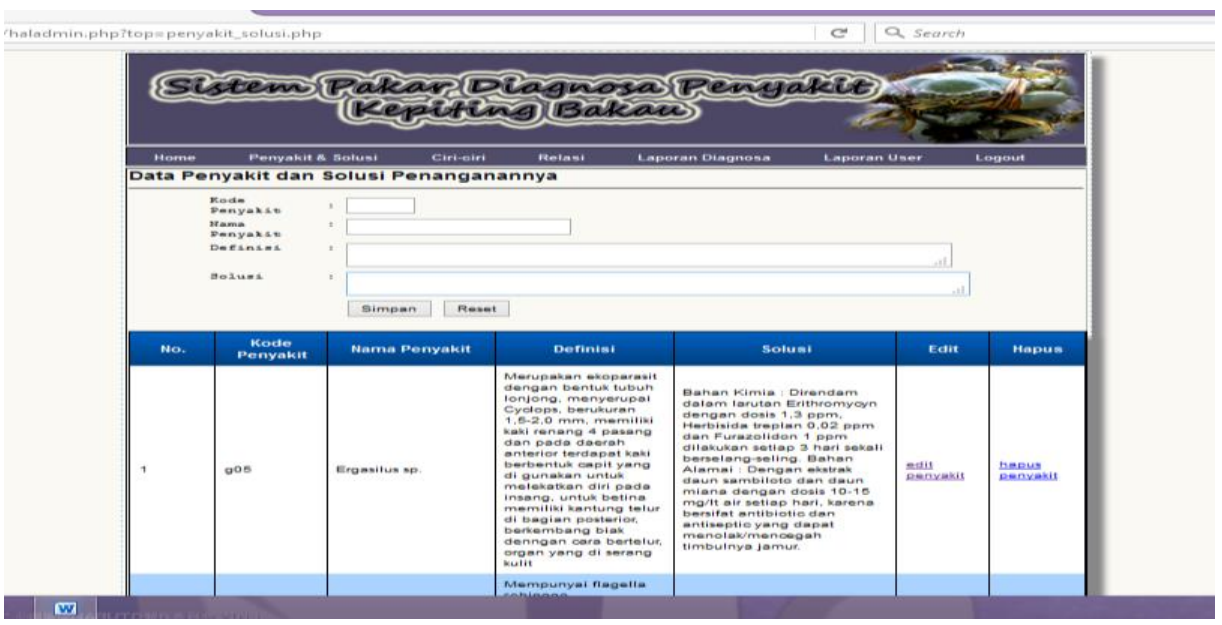

\subsubsection{Halaman Data Ciri-Ciri}

\section{Gambar 4 Halaman Data Penyakit}

Halaman gejala digunakan untuk menginputkan dan menampilkan data gejala. Tampilannya seperti pada gambar berikut :

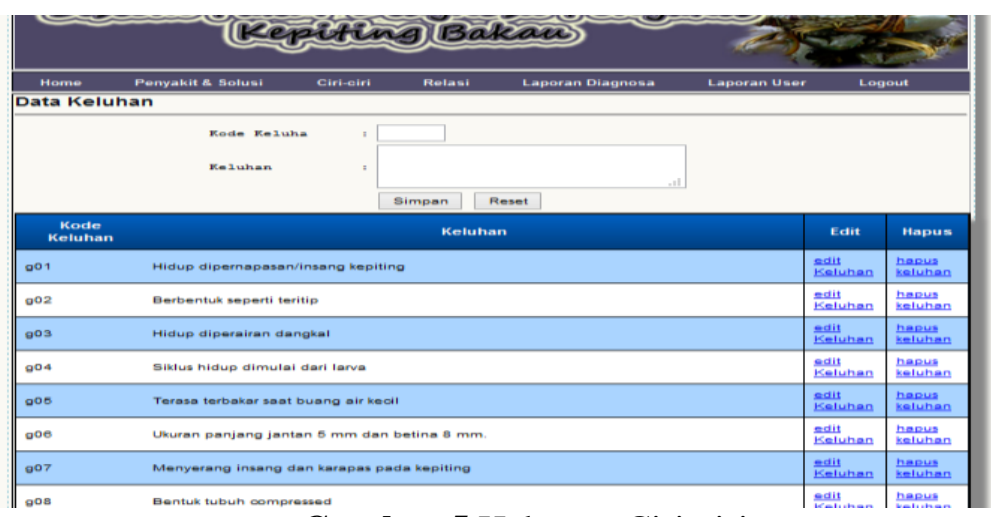

\subsubsection{Halaman Relasi}

Gambar 5 Halaman Ciri-ciri

Halaman input data pasien digunakan untuk menginputkan data pasien yang akan melakukan diagnosa penyakit. Tampilannya seperti pada gambar berikut :

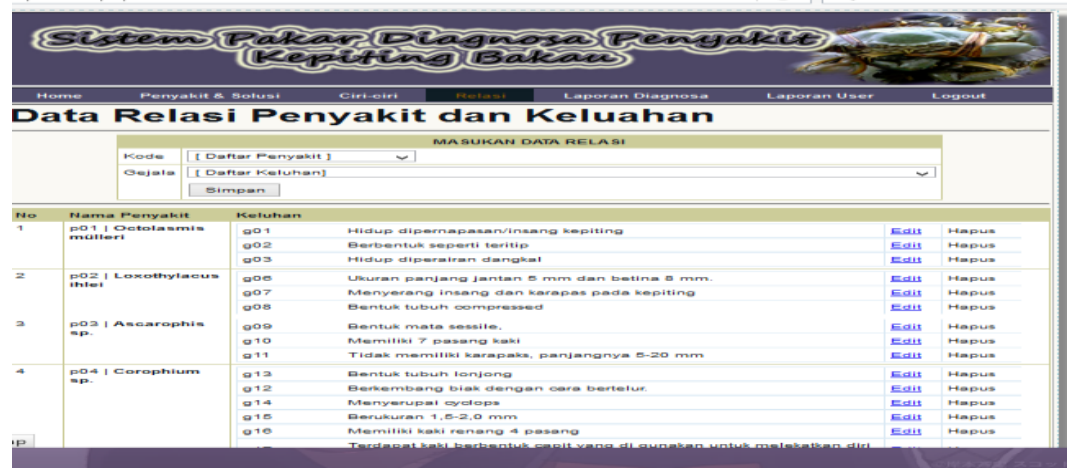

\subsubsection{Halaman Diagnosa}

Gambar 6 Halaman Relasi

Halaman diagnosa digunakan untuk oleh user ketika melakukan diagnosa. Sistem akan mengarah pada registrasi user setelah registrasi sistem akan menampilkan per. Tampilannya seperti pada gambar berikut : 


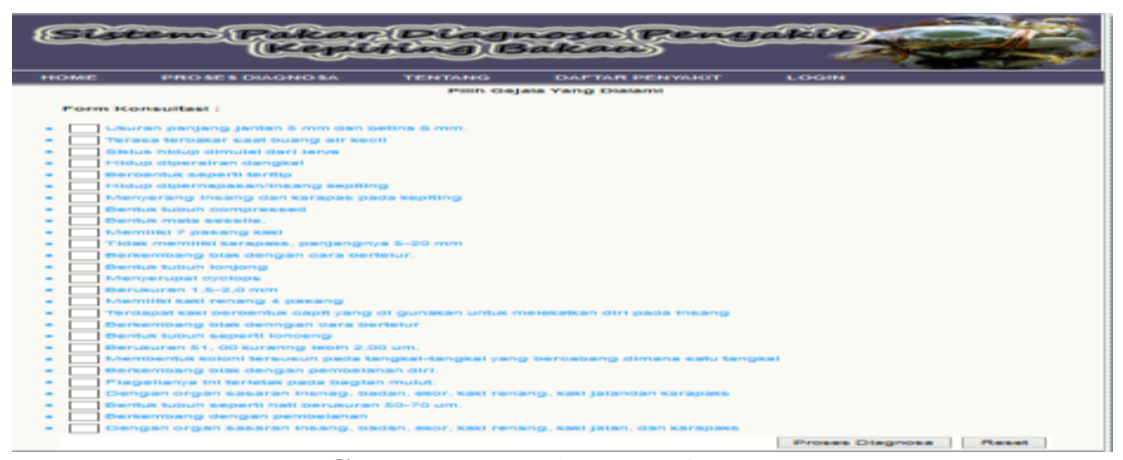

\subsubsection{Halaman Hasil}

\section{Gambar 7 Halaman Diagnosa}

Halaman hasil diagnosa merupakan proses akhir ketika user melakukan diagnosa.Sistem akan menampilkan hasil diagnosa yang telah di pilih oleh user. Seperti pada gambar berikut :

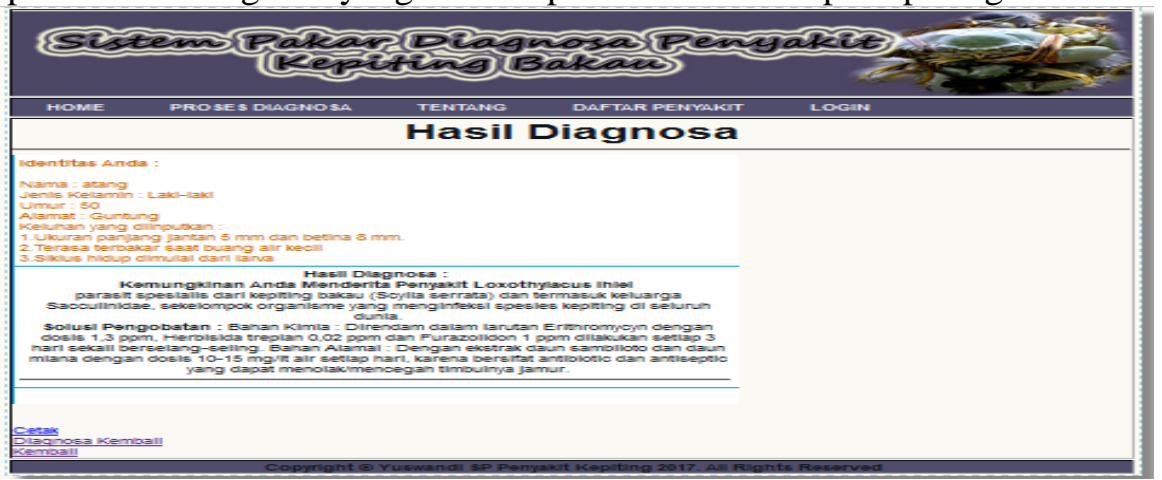

Gambar 8 Halaman Hasil Diagnosa

\section{$5.1 \quad$ Kesimpulan}

Adapun hasil kesimpulan dalam implementasi perancangan sistem dalam penelitian ini yaitu sebagai berikut :

1. Sistem pakar diagnosa penyakit kepiting bakau adalah sebuah sistem yang dapat membantu petambak atau penampung dalam mengatasi penyakit kepiting bakau. Mendiagnosa ciri-ciri yang mungkin pada kepiting sehingga penyakit dapat dideteksi.

2. Menjadikan sarana konsultasi bagi para pembudidaya ataupun penampung kepiting bakau dalam melakukan diagnosa penyakit sehingga dapat membantu para pembudidaya dan penampung serta memperoleh informasi penanganan penyakit pada kepiting.

\subsection{Saran-Saran}

Adapun saran-saran dari penulis untuk penggunaan aplikasi sistem pakar diagnosa penyakit kepiting bakau guna menambah kinerja aplikasi yang harus diperhatikan adalah sebagai berikut :

1. Keberadaan sistem ini diharapkan dapat dimanfaatkan secara maksimal agar dapat mempermudah pengguna dalam mendeteksi penyakit kepiting bakau.

2. Pengguna program disarankan untuk memperhatikan kekurangan-kekurangan dan kelemahankelemahan yang ada agar dapat di cari pamecahan masalahnya dan dapat segera diperbaiki.

3. Pengguna program disarankan untuk memperhatikan kekurangan-kekurangan dan kelemahankelemahan yang ada agar dapat di cari pamecahan masalahnya dan dapat segera diperbaiki.

4. Bagi admin web agar dapat memeriksa pengguna-pengguna yang melakukan registrasi tidak valid dan disarankan dapat menghapusnya dari database agar tidak terjadi spam..

\section{DAFTAR PUSTAKA}

Al-Bahara Bin Ljamuddin., (2005), Analisis dan Desain Sistem Informasi , Graha Ilmu, Yogyakarta.

Andi Sunyoto, (2007), Pemograman Database dengan Visual Basic Dan Microsoft SQL, Andi, Yogyakarta.

Efrain Turban, dkk, (2005), Decision Suport Systemsand Intelligent Systems, Andi, Yogyakarta. 
Jogiyanto, HM ., (2005), Analisis dan Disain Sistem Informasi, Andi Offset, Yogyakarta

Kadir, Abdul , (2003), Pengenalan Sistem Informasi, Andi, Yogyakarta.

Kusrini, (2006), Sstem Pakar teori dan Aplikasi, Andi, Yogyakarta.

Kusrini, (2007), Strategi Perancangan dan Pengolahan Basis Data, Andi, Yogyakarta.

Kusrini, (2008), Aplikasi Sistem Pakar, Andi, Yogyakarta.

Sri Hartati, iswanti, (2008), Sistem Pakar dan Pengembangannya, Graha Ilmu, Yogyakarta. Kusrini, (2008), Aplikasi Sistem Pakar, Andi, Yogyakarta.

Sri Hartati, iswanti, (2008), Sistem Pakar dan Pengembangannya, Graha Ilmu, Yogyakarta.

Wijayakusuma, Hembing, (2008), Ramuan Lengkap Herbal Taklukkan Penyakit, Pustaka Bunda, Jakarta.

Wijayakusuma, Hembing, (2008), Tumpas Hepatitis dengan Ramuan Herbal, Pustaka Bunda, Jakarta.

Wijayakusuma, Hembing, (2008), Bebas Penyakit Ginjal dan Saluran Kemih, Pustaka Bunda, Jakarta. 